Article

\title{
What Will Make Energy Systems Sustainable?
}

\author{
Angela Köppl ${ }^{1, *}$ and Stefan P. Schleicher ${ }^{2}$ \\ 1 Austrian Institute of Economic Research, 1030 Vienna, Austria \\ 2 Wegener Center for Climate and Global Change, University of Graz, 8010 Graz, Austria; \\ stefan.schleicher@uni-graz.at \\ * Correspondence: angela.koeppl@wifo.at; Tel.: +43-179-8260-1268
}

Received: 8 June 2018; Accepted: 16 July 2018; Published: 19 July 2018

\begin{abstract}
Despite the success of the German Energiewende in increasing the production of electricity from renewables and the positive global spillover effects of renewable technologies, one of the lessons learned is the insight that simply shifting to renewables and recommending improving energy efficiency is not sufficient to lower greenhouse gas emissions. Combined with the expected radical change of technologies, this requires a more profound understanding of our energy systems. Therefore, in contrast to many conventional energy economy approaches, we propose a deepened structural analysis that covers the full energy value chain from the required functionalities for mechanical, thermal and specific electric energy services via application and transformation technologies up to primary energy. This deepened structural approach opens and substantially enhances our understanding of policy designs that are compatible with the Paris Agreement and Sustainable Development Goals. We discover the essential role of four energy grids, namely for electricity, heat, gas, and information as the key for integrating all components of a newly structured energy system. Consequently, we conclude that policy strategies focusing on individual components of an energy system like shifting to renewables may, from a comprehensive perspective on more sustainable energy systems, prove even counterproductive.
\end{abstract}

Keywords: sustainable energy systems; energy value chain; energy grids

\section{Introduction}

Energy systems face far reaching changes substantiated on the one hand by the Paris Agreement [1] and on the other by deep technological change [2-4]. Both challenges are closely interlinked if one focuses on targeted technological breakthroughs, as building structures that collect more energy than they consume, mobility that is partially fulfilled by advanced information technologies, e.g., based on holography, or grid structures for electricity, heat and gas that are coupled and become bi-directional. Ultimately this might have decisive impacts on economic structures that foster the qualities of the sustainability of energy systems. What this really means for the transformation of energy systems is less obvious. This is one of the lessons learned from the German effort under the heading of Energiewende [5] as the focus on the phase-out of nuclear led to a shift to electricity from renewables but turned out to be not sufficient for a decisive reduction of greenhouse gases. Although this deliberate policy effort has triggered the take-off of wind power and photovoltaics on a global scale and renewables account now for about one third of electricity production, greenhouse gas emissions in Germany have not significantly decreased [6,7]. Substantial challenges remain like the phase-out of coal for which a Federal Government Commission was appointed, or the improvement of energy efficiency on all layers of the energy value chain.

Since energy systems are intimately woven into any other resource use for personal or business purposes, the same caveats and restrictions apply, as observing the planetary boundaries [8] or the 
Sustainable Development Goals [9]. Given this perspective, we provide operational guidelines for putting energy systems on a sustainable trajectory that encompass much more than the conventional recommendations of shifting to renewables and improving energy efficiency. Although fully covering sustainability qualities is not trivial and not the focus of this paper, we emphasize the qualities of low energy and low carbon for more sustainable energy systems. We put forward the proposition that this requires a deepened understanding of the internal structure of energy systems, ranging from the still not well-known functionalities for thermal, mechanical and specific electric services via the full energy value chain up to primary energy. This opens a broader perspective on targeted transitions of our energy systems that emphasizes the role of grids and technological innovations on each layer of the energy value chain in addition to the substitution of fossil energy sources by renewables. This approach enables handling the implication of radical technological change and allows the discovery of synergies from a much better integration of all components of the energy system. As a key result we obtain insights about the role of newly designed energy grids for electricity, heating and cooling, gas and information technologies as contributing to sustainability.

\section{A Framework for Integrated Energy System Analysis}

For analyzing radical transformations of energy systems along sustainable trajectories, a deepened structural analysis provides guidance for transition strategies. This effort is closely tied to the need for advancements in analytical approaches since current modelling approaches face limitations when it comes to their ability to deal with the long-term evolution of technologies and economic structures as addressed e.g., by [10-12].

\subsection{The Limits of Conventional Approaches to Analyzing Energy Systems}

There is emerging evidence that existing methodological approaches to analyzing energy systems need to be further enhanced to discover the subtleties of long-term transformation processes. Mainstream economic modelling designs as econometric, computable general equilibrium, New Keynesian or complex Integrated Assessment models (IAMs) in general are characterized by an almost complete absence of details of the complete energy value chain [13], in particular they lack to model the central role of functionalities-namely the thermal, mechanical and specific electric services-that are provided by the interaction of energy flows and corresponding capital stocks. Focusing on the entire energy value chain, starting from these functionalities up to primary energy, provides a perspective on energy application and transformation that allows integrating relevant technological innovations on each layer of the energy chain just as the substitution of fossil energy sources by renewables.

With such a deepened view of the energy system, we put forward the following proposition: Since many suggestions for a sustainable transformation of current energy systems have turned out to be too simplistic by focusing mainly on the substitution of fossils by renewables, we propose that in the context of energy sustainability this requires lowering total energy flows without compromising the required functionalities instead of only relying increasingly on renewables. Consequently, we emphasize the need for a deepened understanding of the complete structure of energy systems which also reveals the essential role of four grids—electricity, heating and cooling, gas, and information-that need to interact.

\subsection{Revealing the Full Energy Value-Chain}

Our deepened structural modelling approach to identifying sustainable energy systems builds on two key features: We focus on functionalities for thermal, mechanical and specific electric services as the ultimate purpose of any energy system; then starting from these functionalities we analyze the full energy value chain via application, transformation and storage technologies until we arrive at primary energy needs. This deepened structural view of energy systems as depicted in Figure 1 reveals the essential role of integrating grids that will be operated in bi-directional modes and deal 
with interactions between them. The grid structure in an advanced energy system encompasses more than a separate perspective on electricity, heat or gas grids. In a highly efficient energy system, the new role of grids for gas and the integrating role of information grids have to be taken into account and imply above all that electricity needs to be coupled with heat.

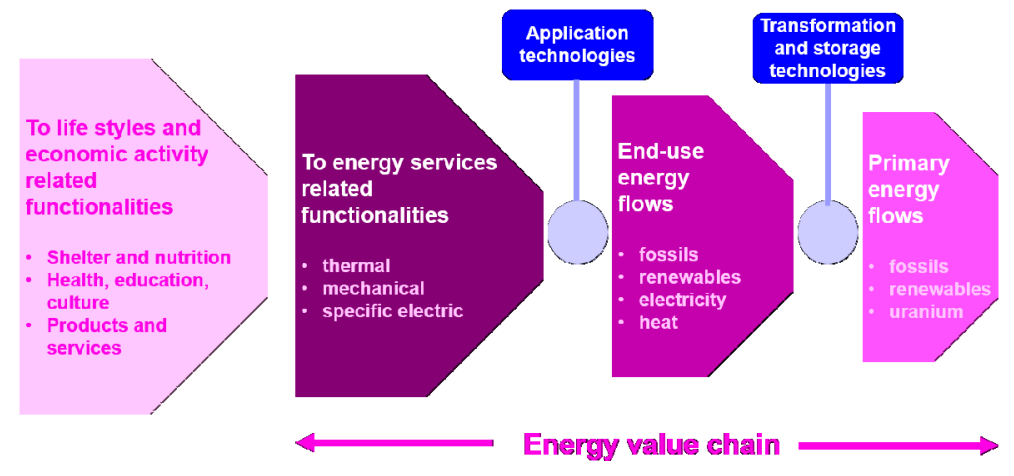

Figure 1. Revealing the entire energy value-chain. Source: Adapted from [14] and [15].

This conceptual framework for energy system analysis is based on previous analytical work that applies this deepened structural modelling as a methodological approach [14-17] and is described in a more formal way in Appendix A. It recommends an alternative way for long term analyses of decarbonized structures, as the current understanding of the energy, emission and economic system, that mainly focuses on the availability of (energy) resources, prices and the close correlation between GDP growth, resource use and emissions, is increasingly questioned (cf. [18]), as is GDP as a measure for wellbeing (e.g., [19]). In the context of long-run transformation research (e.g., [20,21]), interest is growing on how to define and measure human well-being meaningfully and in a way that respects planetary boundaries [22-24]. This is of utmost relevance for the energy system where we already observe far reaching transitional processes. Examples are the emerging integrated micro-grids for universities, business and residential areas [25,26].

Most mainstream energy and emission analysis (cf. [27]) put a strong focus on energy flows and the generated greenhouse gas emissions whereas our deepened structural modelling approach strongly emphasizes the crucial role of functionalities and their dependence on the stocks of technologies used together with energy flows along the full energy value chain up to primary energy.

With this perspective we depart from conventional analysis that typically chooses the availability of primary energy as a starting point. Emphasizing functionalities and the entire energy value chain in contrast allows to stress and analyze the role of different application and transformation technologies in generating energy services, e.g., for the functionalities in buildings and for mobility as well as the transformation and storage for electricity and heat. This goes far beyond concepts that mostly deal with incremental technological progress driven by changes in relative prices as in many mainstream analytical approaches. Such an integrated perspective of the whole energy value chain demonstrates that the different layers are interlinked and therefore should be addressed jointly. It starts from the demand side, the desired functionalities, and connects it to the production side via investment activities and energy flows during the operating phase over the whole lifetime of the capital stocks. We argue that this deepened structural approach is a promising method for understanding and evaluating the expected radical transformations of energy systems.

\subsection{Underlining the Interaction between Energy Flows and the Related Capital Stocks}

Essential for a better understanding of these challenging transition processes is the focus on functionalities, the ultimately expected energy services, which result from the interaction between stocks and flows, to serve (basic) human needs such as shelter, nutrition, health, education and culture. The thermal services in buildings e.g., depend on the quality of the building stock and the related 
energy flows. Mobility is from a functionality perspective the access to persons, goods and locations, and depends on different spatial allocations of economic activities, locations for residence, transport technologies, transport modes and increasingly communication technologies as tele-conferencing and tele-working.

This aspect of the deepened structural modelling approach highlights the interaction between capital stocks (including technologies they represent) and flows for providing a specific functionality. The diffusion and use of technologies that are often characterized by disruptive change impact the energy and emission system on the one hand and shape economic structures on the other. Disruptive change, from an analytical point of view, can arise from a shift in the focus from economies of scale, e.g., cost reductions with increasing scales of production, to also consider economies of scope, e.g., by using cogeneration technologies for electricity and heat. Such changes strongly concern and affect investment decisions that result from an integrated view of the energy system or new options for decentralized structures but also comprise changes in behavior, lifestyles, social practices, and business models.

The focus on functionalities and the relevance of the interaction of stocks and flows is illustrated in Figure 2. The curve illustrates a specific constant functionality that results from resource flows and capital stocks. The constant level of a specific functionality is provided by a combination of the capital stock and resource flows. Along the curve to the right are those combinations where a larger capital stock, e.g., more public transport or a capital stock of higher thermal quality, e.g., buildings with an improved thermal quality, requires much less resource flows for the provision of the required functionality.
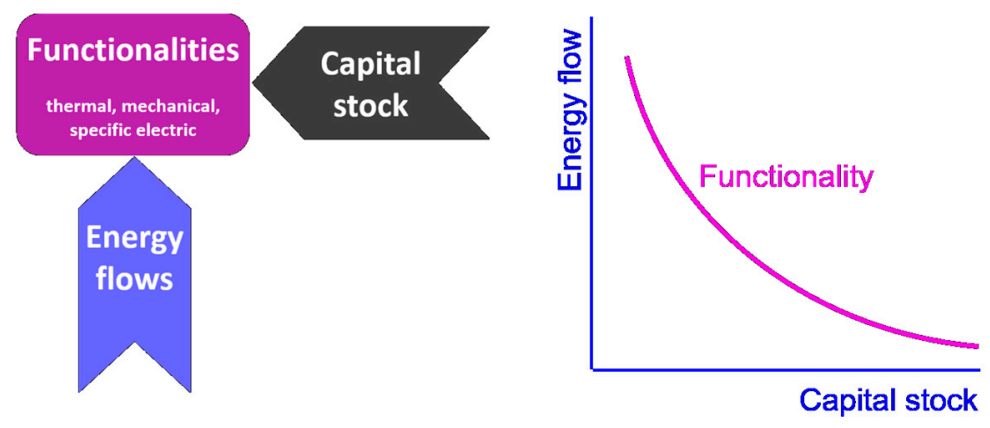

Figure 2. Relevance of stocks and flows for providing functionalities. Source: Adapted from [16] and [15].

\section{The Role of Grids for Sustainability of Energy Systems}

What was overlooked so far in most long-term visions of targeted transitions of energy systems are the interdependencies between the different layers along the energy value chain that need to be considered when providing the thermal, mechanical and specific energy services summarized under the heading of functionalities. Key elements for enabling these interactions are the grids for electricity, heating and cooling, and gas. These grids, however, will also be subject to fundamental transformations that are revealed by adding an integrating information grid.

\subsection{General Guidelines for Sustainable Transition Trajectories}

This extended view of an energy system offers insights about the internal structure and options for change and improvements. Identifying these options requires a much subtler argumentation than substituting fossils by renewables and improving energy efficiency. At least three qualities of an energy system need to be considered for a transition to a low-energy and low-carbon structure, which are necessary for sustainability requirements.

Firstly, we aim for a lower amount of energy for providing the expected functionalities or energy services, e.g., by improving the thermal structure of buildings. This criterion is based on the First 
Law of Thermodynamics, which is referred to as mass efficiency. Secondly, it is the quality and not only the quantity of energy that is applied to provide a functionality, which calls for considering the ability of an energy source to provide mechanical work. This criterion is based on the Second Law of Thermodynamics, which is known by the term exergy efficiency. Thirdly, for the decarbonization of the energy system, a reduction of the amount of fossils in the mix of primary energy is needed. Together these three criteria provide operational guidelines for the transformation of energy systems as illustrated by the following examples.

Buildings currently typically consume a third of final energy, mainly for low-temperature energy services. According to our criteria for the design of energy systems that meet the long-term transition targets, it follows that a high mass efficiency by improving the thermal structures is desirable. In addition, a waste of exergy efficiency should be avoided. This would be the case if low-temperature heat is provided by energy sources with a high but unused ability to provide mechanical work, as electricity, oil products or gas.

Transport typically uses another third of final energy, mainly fossil fuels and some electricity for rail transport and e-mobility. Besides strategies that reduce the need for transport-as a localization of production and the application of communication technologies-a significant increase in the number of electrical drive systems is expected over the next years. The evolution of this technology, however, will strongly depend on battery technologies, the infrastructure for battery charging, but also the strategies of the automotive industry.

The last share of final energy is needed for industry and manufacturing. A main determinant is the industry structure of the economy, in particular the share of energy-intensive industries of a country. Sectoral roadmaps for low-energy and low-emission structures in industry are emerging, e.g., for cement, steel, paper and pulp industry [28].

Final energy results from the transformations of primary energy. If we scrutinize these processes with respect to mass and exergy efficiency criteria, potentials for the desired transition of energy systems emerge. Special attention deserve thermal processes, which typically use stand-alone technologies, such as providing just heat or just electricity. According to the Second Law of thermodynamics, it is highly recommended to switch to cogeneration technologies which exploit besides thermal also mechanical services. Thus, from one input, e.g., gas, two outputs are generated, namely heat and electricity, which in turn can be used for heat pumps that collect free ambient heat. Such a setup substantially increases the efficiency of primary energy.

\subsection{Discovering Synergies via Integrated Grid Structures}

Several implications follow from this comprehensive view on energy systems for the future role of grids in view of the proposed criteria for evaluating them.

Given the decisive role of functionalities, four grids need to be considered simultaneously: electricity, heating and cooling, gas, and an information grid that serves as a tool for coordination. Defining characteristics of a new grid structure will be a shift from uni-directional to bi-directional operation. Compared to the current centralized structures this implies a decentralized design for electricity generation that blurs the distinction between generation and consumption, a new understanding of thermal grids that integrates the recovery of thermal waste, and an increasing use of current gas grids for biogas and even hydrogen.

Such a perspective requires a move from the current structure of separated grids towards integrated structures. This is obvious for the linkage between electricity and heat if thermal processes are involved in the transformation of primary energy. A very innovative development is the design of so-called anergy grids for heat, which typically are operated at low temperatures, e.g., between 15 and 30 degrees Centigrade, and allow the recycling of waste heat, e.g., from sewage water.

Thus, all elements of the energy system, namely functionalities, application and transformation technologies, including thermal and electric storage devices, will be part of an integrated grid structure and can be seen as a prerequisite for long-term sustainability qualities. In contrast to the prevailing 
focus on single elements of the energy system, the integrated view on supply and demand facilitates balancing the load of the grids. Such an enhanced understanding of the interactions of all components of an energy system in particular allows the integration of the increasing contribution of volatile renewables as photovoltaics and wind. Furthermore, this view offers the opportunity to harvest synergies when moving to low-energy and low-emissions structures. Essentially this is a shift from the traditional concept of economies of scale to the innovative concept of economies of scope.

\subsection{Stimulating the Innovation of Grid Structures}

From this deepened structural approach to understanding energy systems, operational guidelines for the restructuring of energy systems can be developed.

Buildings should become multifunctional in the sense that it is not sufficient to improve their thermal quality, but it is also essential to make them an active component in the supply and storage of energy. This implies using the physical structure of the buildings as a thermal storage device by integrating thermal exchangers for heating and cooling into the building envelope. In addition, the building foundations can be endowed with thermal storage capacity that can be used even over seasonal periods. Additionally, buildings can provide infrastructure for installing photovoltaics, high-efficient cogeneration units and heat pumps but also storage devices for electricity and heat.

Interlinked mobility promotes an evolutionary understanding of transport by focusing at the services of access to persons, goods, and locations, and the emerging evidence that these services might not always require a transport activity, given the advances in communication technologies. A comprehensive perspective includes zoning concepts that aim for low distances for all activities related to work, personal needs, and leisure. These ambitions might be encouraged by breakthrough technologies, as additive manufacturing, also known as 3D-printing, and holographic communication technologies.

Integrated grids link electricity, heating and cooling, and gas via information technologies that communicate with relevant elements of the energy system, from appliances up to storage devices. Ultimately this would lead to the diffusion of smart grids with the vision of an internet of things. There are still many uncertainties about how these integrated grids structures should look both with respect to their scale and scope but also their resilience and data security. An energy system, however, that aims at meeting sustainability qualities, by targeting low-energy and low-emissions for providing the welfare-relevant energy services, will need to give grid structures top attention but at the same time without neglecting vulnerability and resilience aspects of the system.

\subsection{Interdependencies of Integrated Grids}

We want to visualize these integrated grid structures in Figure 3; it is inspired by the Swiss Energy Reference Book [29]. The core of the energy system is the functionalities to be provided for building structures, mobility and the production sector.

Shown are three energy grids, namely for electricity, heating and cooling, and gas, which operate in a bi-directional mode and are encompassed by an information grid which may link and control any component of the energy system. Several insights arise from these structures which can already be observed in implementations, notably in Switzerland [26] and in the United States [25]. This design is often labelled as micro grid although the term integrated grid gives a better understanding.

Typically, the grid for electricity is expected to dominate the whole energy system. Electricity is used for specific functionalities as lighting and electronics but also for motors in appliances and increasingly in mobility and production processes. In line with a prosumer concept, electricity is in addition fed into the grid from locally installed photovoltaic panels or wind turbines in close distance and from a new generation of highly efficient small-scale cogeneration units. Altogether such local electricity grids have the potential of supporting the public grid by load-balancing services. 


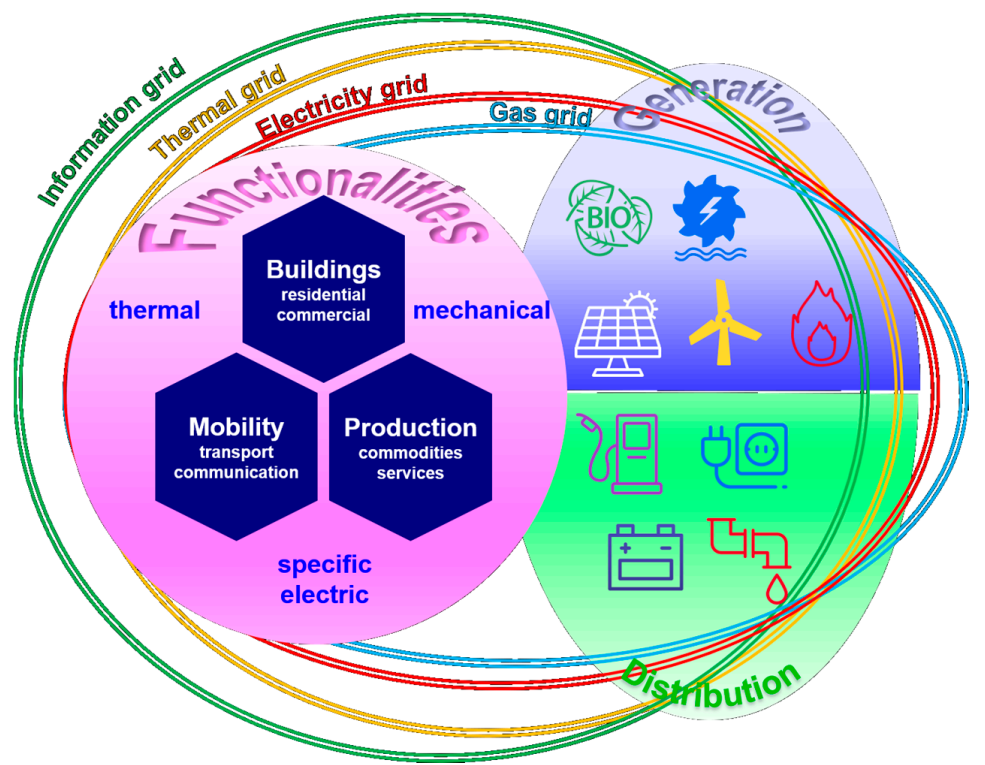

Figure 3. Four interdependent grids integrate the energy system. Source: Authors and [30].

The next game changers are the new electric storage devices which promise a similar cost decline as could be observed for photovoltaics over the past 10 years. Even the batteries of electric cars could provide storage services when not in motion and linked to the electric grid. An additional feature in this next generation of electric grids could be the link to the thermal grid via cogeneration technologies based on turbines, combustion engines, and fuel cells. Surplus electricity from volatile renewables as PV and wind could be converted via electrolyzers to hydrogen, which could then be fed into the conventional grid for gas or even put into seasonal underground storage facilities.

The new thermal grid based on an anergy design can be used for heating and cooling. Sources are thermal solar, heat from cogeneration but also from heat pumps and geothermal sources. Such a thermal grid supplies heat during the winter season and cooling during the summer season.

The redundancy of a full areal coverage of end users in residential or commercial buildings is driving the change in gas grids. Parts of the current grid may be used, however, to transport gas for local cogeneration units and may gradually be fed by gas from biogenic sources like organic waste and even hydrogen.

Altogether Figure 3 shows that an energy system that aims for high energy productivity and low greenhouse gas emissions needs a newly integrated grid design which goes far beyond the current understanding of a smart electricity grid. These innovative grid designs increasingly exhibit smaller scales as well as localized and clustered structures.

\subsection{Economic Aspects of an Integrated Energy System}

This new shape of the energy system, looked at through the lens of functionalities as delineated above, could be described by the keywords decentralized, clustered and integrated.

Adopting, however, such a perspective needs to be mirrored in investment decisions and economic evaluation on the one hand and a supporting policy framework on the other. This is particularly true for cost assessments. We stress that the user costs for a specific functionality, composed of annualized capital cost and annual operating cost, are the relevant measure for evaluating any investment decision to arrive at a more sustainable energy system since the user cost of functionalities clearly reflect the combined effect of the investment and operating costs over the whole lifetime of an investment. We also argue that this link of cost considerations to functionalities allows overcoming the often-observable focus on fragmented energy issues, like the substitution of fossil energy sources by renewables, the focus on electricity, e-mobility or any other specific component of the energy system. 
Buildings are a good example for illustrating the relevance of the user cost of functionalities. Currently housing developers typically expect a return on investment characterized by short-termism that clearly falls short of considering the lifetime of a building and costs over the whole operating period. Consequently, this gives established technologies an advantage over innovative technologies that might have higher investment costs but lower operating costs. Distortions like these would be revealed when focusing on user costs of functionalities.

An even more far-reaching perspective is opened by the Paris Agreement [1], which calls for a radical phaseout of greenhouse gases until mid-century. Any current investment based on fossil fuels with a life-time over several decades is exposed to becoming a stranded asset. Energy grids are long-lived infrastructures; their design therefore plays a key role in making a transition to a sustainable energy system possible.

\section{Conclusions for Policy-Makers and Research}

The new framework for energy analysis as presented here argues that sustainable energy structures require a new perspective and fundamental restructuring of the energy system. A key to this new mindset is the focus on the functionalities to be provided and the deepened structural view of the energy value chain that finally determines the amount of primary energy and the related greenhouse gas emissions. Essential is the integrating role of the grids for electricity, heating and cooling, gas, and information. This raises new research questions in energy economics and energy modelling since many energy and energy-economy models still rely on path dependency of past developments and prevailing structures, thus lacking the potential for analyzing expected radical structural changes. Research also needs to focus on barriers stemming from prevailing structures in administrative bodies, the regulatory framework, business models and production processes of companies. Such research is of high complexity and requires a thorough analysis of the economic impact it might trigger.

Most currently visible energy policies are characterized by a lack of system thinking and often show a focus on single elements as renewables or electric mobility. This might hold, e.g., if investment opportunities for energy generation capacities are not compared to investment options for increasing energy productivity in application technologies in an approach that integrates the investment and operating phase. In this case, policy strategies focusing on individual components of an energy system may from a comprehensive perspective on sustainability in the worst case even turn out as counterproductive.

An orientation on long-term sustainable energy systems thus requires a more differentiated argumentation of policy goals and policy instruments. With respect to buildings e.g., simply focusing on renovation without clear quality standards and an assessment of costs and emissions over the whole lifetime of the building will not meet the requirements of deep structural changes for accomplishing sustainability criteria. A more differentiated argumentation is also needed for single policy recommendations, such as carbon prices. Undoubtedly, carbon pricing is an essential instrument for facilitating changes in the energy system. A uniform price, however, may not meet the requirements for change that prevail in different sectors of an economy.

Our suggested framework emphasizes that more sustainable structures of an energy system cannot be assessed by single measures, instruments or indicators but only by the interaction of all components ranging from functionalities to primary energy. Thinking in integrated grids is a very operational vehicle to promote such deepened system thinking and reveals that energy system issues need to be mirrored and embedded in broader policy areas like public finance, industrial policy or research policy. 
Author Contributions: Both authors produced this manuscript jointly. It is based on previous research cooperation. Both authors contributed to the manuscript in a similar extent. The formal presentation in Appendix A is provided by Stefan Schleicher.

Funding: Funding for previous projects by the Austrian Climate and Energy Fund and Austrian ministries is kindly acknowledged.

Conflicts of Interest: The authors declare no conflict of interest.

\section{Appendix A. The Analytical Framework of the Deepened Structural Approach to Energy Systems}

The deepened structural approach to modeling energy systems identifies at least three layers that are embedded in an onion-like shape. At its core is the physical system that interacts with the socio-economic system. Both are exposed to the institutional system with its mechanisms for coordination and incentives. We provide in a nutshell the building blocks of this modeling approach, which are the defining characteristics of a model family under the acronym sGAIN (sustainable general analysis of innovative notions). More details can be found in [18].

Appendix A.1. Focusing on the Physical Structure of the Energy Value Chain

The backbone of the physical structure of an energy system is the energy value chain starting with the functionalities $F$ for energy services and spanning via final energy $e^{f}$ to primary energy flows $e^{p}$. The relevant technologies involved are the application technologies $t^{F}$ that provide the functionalities and the transformation technologies $t^{T}$ that convert primary energy to final energy. These technologies are parameterized as productivities which depend on the corresponding capital stocks $K^{F}$ and $K^{T}$.

Thus, the physical structure is described by equations for the various types of final energy flows

$$
e^{f}=t^{F}\left(K^{F}\right)^{-1} F
$$

and primary energy flows

$$
e^{p}=t^{T}\left(K^{T}\right)^{-1} e^{f}
$$

Greenhouse gas emissions $g$ are linked to primary energy flows $e^{p}$ by the emissions intensity of fossil energy $g_{0}^{f o s}$ which in turn depends on the distribution of the fossil energy mix $\operatorname{distr}\left(e^{p, f o s}\right)$. The share of fossil energy in total primary energy follows after subtracting the shares for renewable energy $s^{p, r e s}$ and nuclear energy $s^{p, n u c}$. Thus, greenhouse gas emissions are obtained by

$$
\left.g=g^{f o s}\left(\operatorname{distr}{ }^{e p, f o s}\right)\right)\left(1-s^{p, r e s}-s^{p, n u c}\right) e^{p} .
$$

This parametrization of the physical structure of an energy system is valid for any scale, from a household and a company up to a region or country, and reveals the drivers for energy flows and emissions, namely the amount of functionalities, the energy productivities for application and transformation technologies and finally the energy mix of primary energy.

\section{Appendix A.2. Linking the Physical Energy System with the Economic System}

The basic channels of interaction between the physical energy and the economic system are the flows of final and primary energy and investments for application and transformation technologies.

Using a representative energy price $p^{e}$ we obtain in the economic system the consumption of energy $c^{e}$ in monetary terms as

$$
c^{e}=p^{e} e^{f}
$$

Primary energy in monetary terms enters the economic system as energy supply $s^{e}$ as

$$
s^{e}=p^{e} e^{p}
$$


The physical energy systems effects via investment activities $i$ the economic system both from the changes in capital stocks $\Delta K$ and replacement investments $r$. Thus, investments in the capital stock for application technologies are

$$
i^{F}=\Delta K^{F}+r^{F}
$$

and investments in the capital stock for transformation technologies

$$
i^{T}=\Delta K^{T}+r^{T} .
$$

We split the economic system into an energy and non-energy sector, both with possible further disaggregation.

For the energy sector total supply $s^{e}$ originates from domestic production $q^{e}$ and imports $m^{e}$

$$
s^{e}=q^{e}+m^{e}
$$

and total demand $d^{e}$ from consumption of energy $c^{e}$ and exports of energy $x^{e}$

$$
d^{e}=c^{e}+x^{e} .
$$

For the non-energy sector total supply $s^{n}$ stems from domestic production $q^{n}$ and imports $m^{n}$

$$
s^{n}=q^{n}+m^{n}
$$

and total demand $d^{n}$ from consumption of non-energy $c^{n}$ (for households, companies and the public sector) but also investments $i^{n}$ for this sector and for the application and transformation capital stock energy sector $i^{F}$ and $i^{T}$ as well as exports of non-energy products $x^{n}$

$$
d^{n}=c^{n}+i^{n}+i^{F}+i^{T}+x^{n}
$$

So far, we have deliberately only proposed relationships that describe either physical identities, as in the energy system, or monetary identities, as in the economic system, without claiming any causalities or behavioral assumptions. This is addressed in the next stage of our modeling framework.

\section{Appendix A.3. Adding the Institutional Mechanism for Coordination and Incentives}

We continue by asking how the economic system with its embedded energy system could be driven and shaped by institutions and mechanisms for coordination and incentives. We emphasize, however, that these suggested additional specifications need to be carefully checked with respect to their validity in each case considered.

A first set of interactions proposes causalities from activity levels and relative prices between energy $p^{e}$ and non-energy $p^{n}$.

These are possible specifications for the non-energy sector

$$
\begin{aligned}
c^{n} & =c^{n}\left(q^{n}, p^{e}, p^{n}\right) \\
i^{n} & =i^{n}\left(q^{n}, p^{e}, p^{n}\right) \\
m^{n} & =m^{n}\left(q^{n}, p^{e}, p^{n}\right)
\end{aligned}
$$

and the energy sector

$$
\begin{aligned}
c^{e} & =c^{e}\left(e^{f} p^{e}, p^{n}\right) \\
q^{e} & =q^{e}\left(e^{p} p^{e}, p^{n}\right) \\
m^{e} & =m^{e}\left(e^{p} p^{e}, p^{n}\right)
\end{aligned}
$$


Similar causalities can be proposed also for the functionalities if adequate data are available:

$$
F=F\left(q^{n}, p^{e}, p^{n}\right)
$$

The activity and price elasticities of these specifications can be estimated by econometric methods and need to be checked with respect to stability and validity.

A second set of interactions concerns hypotheses about which coordination mechanisms apply. Although markets seem to be the preferred coordination mechanism for economic activities, this is not necessarily the only coordination mechanism but non market incentives like regulated feed-in tariffs are in place as well if we are dealing with the energy sector. Even if we stick to market mechanism, it is useful to distinguish between a Keynesian type and a neoclassical type of market coordination.

A Keynesian type of market coordination would assume that supply basically adjusts to demand, thus giving less attention to potential supply restrictions. Thus, the quantity equilibrium for the non-energy sector would require

$$
q^{n}+m^{n}\left(q^{n}\right)=c^{n}\left(q^{n}\right)+i^{n}\left(q^{n}\right)+x^{n} .
$$

Similarly, a quantity equilibrium for the energy sector would entail

$$
q^{e}\left(e^{p}\right)+m^{e}\left(e^{p}\right)=c^{e}\left(e^{f}\right)+x^{e} .
$$

A neoclassical type market coordination emphasizes the role of prices for equilibrating demand and supply, thus considering at least some supply restrictions. A neoclassical flavored specification for the non-energy sector postulates, e.g., the dependency of demand and supply components from the domestic price $p^{n}$ and the import price $p^{m}$ :

$$
q^{n}\left(p^{n}, p^{m}\right)+m^{n}\left(p^{n}, p^{m}\right)=c^{n}\left(p^{n}\right)+i^{n}\left(p^{n}\right)+x^{n} .
$$

Under the assumption that there is a price adjustment for products of the non-energy sector towards an equilibrium between supply and demand, this equilibrium price will determine the quantities of the supply and demand components.

For the energy sector, a neoclassical setting would postulate demand and supply relations for final and primary energy and again a price adjustment towards a market equilibrium. Such a price equilibrium could be specified for the energy sector, e.g., by considering the impacts of a domestic energy price $p^{e}$ versus an energy price for imports $p^{m}$ :

$$
q^{\mathrm{e}}\left(p^{e}, p^{m}\right)+\mathrm{m}^{\mathrm{e}}\left(p^{e}, p^{m}\right)=\mathrm{c}^{\mathrm{e}}\left(p^{e}\right)+x^{\mathrm{e}} .
$$

Finally, we want to state that the energy sector typically reflects many economic decisions that are not based on markets but incentives from the non-market agenda, in which vested interests may also be of relevance. This means that there is no one-fits-all specification in energy models, and there is a need for a careful evaluation of all restrictions imposed on the basic structure of the physical and economic specification of an energy system.

\section{References}

1. United Nations Framework Convention on Climate Change (UNFCCC). The Paris Agreement; United Nations Framework Convention on Climate Change (UNFCCC): Bonn, Germany, 2015.

2. MIT Energy Initiative. Utility of the Future; Massachusetts Institute of Technology: Cambridge, MA, USA, 2016; ISBN 978-0-692-80824-5.

3. Heinonen, S.; Karjalainen, J.; Ruotsalainen, J. Radical Transformation in a Distributed Society-Neo-Carbon Energy Scenarios 2050; Finland Futures Research Centre (FFRC), Turku School of Economics: Turku, Finland, 2016; ISBN 978-952-249-415-3. 
4. Breit, S.; Rao, V.; Gürtler, D. A New World of Energy—From Scarcity to Abundance; Gottlieb Duttweiler Institute: Rüschlikon, Switzerland, 2018.

5. Agora Energiewende. The Energiewende in a Nutshell-10 Q \& A on the German Energy Transition; Agora Energiewende-Smart Energy for Europe Platform (SEFEP): Berlin, Germany, 2017.

6. Appunn, K.; Wettengel, J. Germany's Greenhouse Gas Emissions and Climate Targets; Clean Energy Wire: Berlin, Germany, 2018; Available online: https:/ /www.cleanenergywire.org/factsheets/germanys-greenhouse-gasemissions-and-climate-targets (accessed on 18 July 2018).

7. Agora Energiewende. Die Energiewende im Stromsektor: Stand der Dinge 2017; Agora Energiewende-Smart Energy for Europe Platform (SEFEP): Berlin, Germany, 2018.

8. Steffen, W.; Richardson, K.; Rockström, J.; Cornell, S.E.; Fetzer, I.; Bennett, E.M.; Biggs, R. Planetary boundaries: Guiding human development on a changing planet. Science 2015, 347. [CrossRef] [PubMed]

9. United Nations (UN). Transforming Our World: The 2030 Agenda for Sustainable Development; United Nations: New York, NY, USA, 2015.

10. Pindyck, R.S. The Use and Misuse of Models for Climate Policy. Rev. Environ. Econ. Policy 2017, 11. [CrossRef]

11. Rosen, R.A.; Guenther, E. The economics of mitigating climate change: What can we know? Technol. Forecast. Soc. Chang. 2015, 91. [CrossRef]

12. Stern, N. Economics: Current climate models are grossly misleading. Nature 2016, 530, 407-409. [CrossRef] [PubMed]

13. Schinko, T.; Bachner, G.; Schleicher, S.P.; Steininger, K.W. Modeling for insights not numbers: The long-term low-carbon transformation. Atmósfera 2017, 30. [CrossRef]

14. Köppl, A.; Kettner, C.; Kletzan-Slamanig, D.; Schleicher, S.P.; Damm, A.; Titz, M.; Damm, A.; Steininger, K.W.; Wolkinger, B.; Schnitzer, H.; et al. Energy Transition in Austria: Designing Mitigation Wedges. Energy Environ. 2014, 25, 281-304. [CrossRef]

15. Schleicher, S.P.; Köppl, A.; Sommer, M.; Lienin, S.; Treberspurg, M.; Österreicher, D.; Grünner, R.; Lang, R.; Mühlberger, M.; Steininger, K.W.; et al. What Future for Energy and Climate? Impact Assessments for Energy and Climate Strategies; Austrian Institute of Economic Research (WIFO): Vienna, Austria, 2018. (In German)

16. Köppl, A.; Kettner, C.; Schleicher, S.P.; Hofer, C.; Köberl, K.; Schneider, J.; Schindler, I.; Krutzler, T.; Gallauner, T.; Bachner, G.; et al. ClimTrans2050-Modelling Low Energy and Low Carbon Transformations. The ClimTrans2050 Research Plan; Austrian Institute of Economic Research (WIFO): Vienna, Austria, 2016.

17. Köppl, A.; Schleicher, S.P. Energieperspektiven für Österreich-Zielorientierte Strukturen und Strategien; Austrian Institute of Economic Research (WIFO): Vienna, Austria, 2014. (In German)

18. Schleicher, S.P.; Hofer, C.; Schinko, T.; Steininger, K.W.; Jonas, M.; Zebrowski, P. Energy Modeling that Matters for Reality-A Handbook for Deepened Structural Modeling Approaches; ClimTrans2050 Working Paper No. 2; Austrian Institute of Economic Research (WIFO): Vienna, Austria, 2016.

19. Stiglitz, J.E.; Sen, A.; Fitoussi, J.-P. Report by the Commission on the Measurement of Economic Performance and Social Progress (CMEPSP); CMEPSP: Paris, France, 2009.

20. German Advisory Council on Global Change (WBGU). World in Transition-A Social Contract for Sustainability—Summary for Policy Makers; German Advisory Council on Global Change (WBGU): Berlin, Germany, 2011; ISBN 978-3-936191-47-9.

21. Goepel, M. The Great Mindshift-How a New Economic Paradigm and Sustainability Transformations go Hand in Hand; Springer: Berlin, Germany, 2016; ISBN 978-3-319-43766-8.

22. Raskin, P.D.; Electris, C.; Rosen, R.A. The Century Ahead: Searching for Sustainability. Sustainability $2010,2$. [CrossRef]

23. Raworth, K. Doughnut Economics: Seven Ways to Think Like a 21st-Century Economist; Cornerstone: London, UK, 2017; ISBN 978-1-84794-137-4.

24. Helliwell, J.F.; Layard, R.; Sachs, J.D. World Happiness Report 2018; Sustainable Development Solutions Network: New York, NY, USA, 2018; Available online: https://s3.amazonaws.com/happiness-report/2018/ WHR_web.pdf (accessed on 5 June 2018).

25. Wagman, D. First Utility-Scale Microgrid in U.S. Enters Service. IEEE Spectrum, 26 May 2017. Available online: https:/ / spectrum.ieee.org/energywise/energy/the-smarter-grid/first-utilityscale-microgrid-inus-enters-service(accessed on 18 July 2018).

26. Bollinger, L.A.; Evins, R. The Holistic Urban Energy Simulation (HUES) Platform; Empa: Duebendorf, Switzerland, 2017. 
27. Weyant, J.; Kriegler, E. Preface and introduction to “The EMF27 Study on Global Technology and Climate Policy Strategies". Clim. Chang. 2014, 123. [CrossRef]

28. European Commission. The Roadmap for Transforming the EU into a Competitive, Low-Carbon Economy by 2050; European Commission: Brussels, Belgium, 2011.

29. Schweizer Energiefachbuch; Kömedia: St. Gallen, Switzerland, 2016.

30. Flaticon. 2018. Available online: www.flaticon.com (accessed on 5 June 2018).

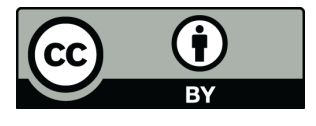

(C) 2018 by the authors. Licensee MDPI, Basel, Switzerland. This article is an open access article distributed under the terms and conditions of the Creative Commons Attribution (CC BY) license (http:/ / creativecommons.org/licenses/by/4.0/). 